\title{
INFLUÊNCIA DA PALHADA DE GRAMÍNEAS FORRAGEIRAS SOBRE O DESENVOLVIMENTO DA PLANTA DE MILHO E DAS PLANTAS DANINHAS
}

\author{
MARCO AURÉLIO NOCE ${ }^{1}$, ITAMAR FERREIRA DE SOUZA², DÉCIO KARAM ${ }^{3}$, ANDRÉ \\ CABRAL FRANÇA ${ }^{4}$ e GABRIEL MASCARENHAS MACIEL ${ }^{5}$.
}

\author{
${ }^{1}$ Embrapa Milho e Sorgo, rod.MG 424, Km 65, 35701-970, Sete Lagoas MG, \\ noce@cnpms.embrapa.br \\ 2Universidade Federal de Lavras, Departamento de agricultura, itamarfs@ufla.br \\ ${ }^{3}$ Embrapa Milho e Sorgo, rod.MG 424, Km 65, 35701-970, Sete Lagoas MG, \\ karam@cnpms.embrapa.br \\ ${ }^{4}$ Universidade Federal de Viçosa (Dft/UFV). Av. Bueno Brandão, 182 ap. 901. Centro, Viçosa, \\ MG, 36570-000, email: cabralfranca@yahoo.com.br \\ ${ }_{5}^{5}$ Universidade Federal de Lavras, Departamento de agricultura, \\ email: gabrielmascarenhasmaciel@yahoo.com.br
}

Revista Brasileira de Milho e Sorgo, v.7, n.3, p. 265-278, 2008

RESUMO - Avaliou-se o efeito da palhada de gramíneas forrageiras (capim braquiarão, milheto e sorgo forrageiro) sobre o desenvolvimento da planta de milho e das plantas daninhas, em experimento realizado na Embrapa Milho e Sorgo, no período de março de 2006 a fevereiro de 2007. Os tratamentos foram constituídos pelas três plantas de cobertura, sofrendo ou não um corte após 60 dias de implantação das parcelas, mais um tratamento sem cobertura (pousio). A cobertura de capim braquiária interferiu negativamente no stand inicial, altura de plantas e de espigas. O diâmetro de colmo das plantas de milho na cobertura de milheto foi inferior. Não houve diferença significativa entre as coberturas e nem destas com relação ao pousio, para os demais parâmetros. Também não houve efeito significativo do corte sobre nenhuma das características agronômicas analisadas e nem para os dados de produção do milho. Nas três espécies de cobertura, os percentuais de redução na infestação de plantas daninhas em relação à testemunha sem palha (pousio) foram altos $\mathrm{O}$ efeito do corte não foi significativo na supressão de plantas daninhas. $\mathrm{O}$ capim braquiária foi superior no percentual de redução da infestação de plantas daninhas e na produção de palha, indicando provável correlação entre as duas variáveis.

Palavras-chave: cobertura morta, Brachiaria brizantha, Pennisetum glaucum, Sorghum bicolor x Sorghum sudanens, Zea mays L. 


\title{
FORAGE GRASS COVER CROPS AND THEIR EFFECTS ON CORN DEVELOPMENT AND WEED INFESTATION
}

\begin{abstract}
This work aimed to evaluate the effect of forage grass cover crops on corn development and weed infestation suppression. The treatments consisted of three cover crops, brachiaria, pearl millet and an interspecific sorghum hybrid (BRS 800), submitted or not to one cut 60 days after planting, and a check plot (fallow land). The experiment was conducted at Embrapa Corn and Sorghum Center, Sete Lagoas-MG, in the period from March 2006 to February 2007. Brachiaria reduced the initial corn stand, plant and ear height, but there was no significant difference in the final stand. Corn stalk diameter was smaller using pearl millet as cover crop. No significant differences were observed among treatments or between cover crops and control for the other parameters. Also, no significant effect of cut was observed on corn agronomic characteristics and grain yield. For the three evaluated cover crop species, weed infestation was considerably reduced when compared to the check plot (fallow land). Cut did not show any significant effect on weed suppression. Brachiaria was superior than sorghum and pearl millet regarding mulch volume and weed infestation reducing, indicating a possible correlation between the two variables.
\end{abstract}

Key words: mulching, Brachiaria brizantha, Pennisetum glaucum, Sorghum bicolor x Sorghum sudanens, Zea mays L.

Uma das premissas básicas do plantio direto é a formação de cobertura morta (palhada) antes do plantio da cultura principal. Tal cobertura, além de contribuir na melhoria das características físicas, químicas e biológicas do solo e na manutenção da temperatura e da umidade do mesmo, pode ser um importante instrumento auxiliar no controle das plantas daninhas. Porém, da mesma forma, a presença de uma camada de palha sobre a superfície do solo poderá influenciar na germinação e/ou no desenvolvimento da cultura implantada em sucessão.

A presença de uma camada de palha sobre a superfície do solo irá influenciar no comportamento de outras plantas, de diversas formas. Há o efeito físico, que limita a passagem de luz e forma uma barreira, inibindo a germinação das sementes e dificultando o crescimento inicial das plântulas. Existem os efeitos químicos, oriundos da decomposição da fitomassa e/ou exsudação, pelas raízes, de 
substâncias denominadas alelopáticas, que podem exercer efeito inibitório na germinação das sementes ou interferir em algum processo do seu desenvolvimento, de tal modo que o crescimento é retardado ou paralisado, havendo casos em que ocorre a morte da planta (Alvarenga et al., 2001). A intensidade de tais efeitos depende do material de origem e da sua incorporação ou não ao solo (Durigan \& Almeida, 1993). O efeito biológico também pode influenciar no comportamento das plantas daninhas, pois a presença da cobertura morta gera condições para a instalação de uma grande quantidade de organismos que podem utilizar sementes e plântulas como fontes de energia.

A intensidade e a persistência dos efeitos da palhada sobre as plantas irão variar de acordo com a espécie utilizada como cobertura e no plantio em sucessão, o volume de palha produzida, as espécies infestantes e o tempo de decomposição da palha pelos micro-organismos do solo. Tokura \& Nóbrega (2005) e Correia et al. (2006) constataram tais efeitos sobre as culturas do milho e da soja, respectivamente, concluindo que os mesmos variaram com a espécie e com o volume de resíduos.

$\mathrm{O}$ efeito de cobertura morta sobre as plantas daninhas também já foi bastante estudado. Vidal \& Trezzi (2004) avaliaram efeitos físicos e alelopáticos e a supressão diferencial de plantas daninhas por genótipos de sorgo e milheto. Os resultados, condicionados ao volume de palha, chegaram a $74 \%$ de redução na matéria seca total de invasoras. Vários outros trabalhos ilustram o efeito de cobertura morta sobre plantas daninhas (Gravena et al., 2004; Erasmo et al., 2004; Mateus et al., 2004; Oliveira et al., 2001).

Nesse contexto, principalmente nas regiões de clima quente e úmido, que ocorre em boa parte do território nacional, predominam as gramíneas tropicais responsáveis pela formação de cobertura morta. Essas espécies têm a característica de produzir grande volume de massa e, por terem alta relação $\mathrm{C} / \mathrm{N}$, persistem por mais tempo cobrindo o solo. Dentre estas, uma boa opção seriam gramíneas de pastoreio, como as braquiárias, o milheto e o sorgo, que são palatáveis para a alimentação de ruminantes e que podem ser de grande interesse para o agropecuarista. A utilização dessas plantas de cobertura na alimentação de ruminantes, em sistema de integração lavoura-pecuária, sem prejuízo para formação da camada de palha, poderá representar uma redução substancial no custo de implantação das mesmas.

Este trabalho teve por objetivo avaliar a interferência da palhada de sorgo para corte/ pastejo, do capim braquiária e do milheto, no desenvolvimento e na produção da cultura do milho e sobre as plantas daninhas. 


\section{Material e Métodos}

O experimento foi conduzido na área experimental da Embrapa Milho e Sorgo, localizado em Sete Lagoas MG, no período de março de 2006 a abril de 2007, em solo do tipo Latossolo Vermelho Distrófico argiloso, de fertilidade média. A precipitação média anual varia de 1.300 a $1.400 \mathrm{~mm}$. Os resultados da análise do solo no local do experimento indicaram: M.O. $=0,87$ dag $\mathrm{kg}^{-1} ; \mathrm{pH}$ em $\mathrm{H}_{2} \mathrm{O}$ $=6,0 ; \mathrm{P}=46 \mathrm{mg} \mathrm{dm}^{-3} ; \mathrm{K}=174 \mathrm{mg} \mathrm{dm}^{-3} ; \mathrm{CTC}$ $=8,54 \mathrm{cmolc} \mathrm{dm}^{-3}$; saturação de bases $=66 \%$.

O delineamento experimental foi o de blocos ao acaso, com quatro repetições, em esquema fatorial $3 \times 2$. Os tratamentos foram constituídos pela combinação de três espécies de plantas de cobertura de solo: cultivar de sorgo BRS 800 para corte/pastejo (híbrido interespecífico Sorghum bicolor x Sorghum sudanens), capim braquiarão (Brachiaria brizantha) e milheto, cultivar BRS 1501 (Pennisetum glaucum), sofrendo ou não um corte após 60 dias de implantação das parcelas. Alem desses tratamentos, manteve-se uma parcela sem o plantio, denominada pousio.

O plantio das plantas de cobertura do solo foi realizado em março de 2006, não recebendo nenhum tipo de adubação. A semeadura foi mecanizada, usando o espaçamento de $35 \mathrm{~cm}$ entre linhas, para as três espécies. As dimensões da parcela foram de $10 \mathrm{~m}$ de comprimento por 4,20 m, correspondendo a 12 linhas de plantio. Nas parcelas correspondentes ao pousio, não houve o semeio das espécies de cobertura. Em maio de 2006, foi realizado o corte da forragem, de forma a simular um pastoreio naquele período, nas parcelas correspondentes aos tratamentos "com corte". A forragem cortada foi retirada da parcela. Em outubro do mesmo ano, foi realizada a primeira dessecação da área, com herbicida a base de glyphosate $\left(720 \mathrm{~g} \mathrm{ha}^{-1}\right) \mathrm{e}$, no mês seguinte, em novembro, foi necessária nova dessecação, para controlar a rebrota das plantas de cobertura, com a mesma dose de glyphosate, de forma a permitir o plantio mecanizado do milho. O plantio do milho foi realizado dez dias aproximadamente após a última aplicação do dessecante, com o híbrido simples BRS 1001, espaçamento de $70 \mathrm{~cm}$ e adubação de plantio de $300 \mathrm{Kg} \mathrm{ha}^{-1}$ da fórmula 08-28-16. Foi feita a adubação nitrogenada de cobertura, 30 dias após o plantio do milho (DAP), utilizando uréia incorporada. Buscouse obter, na semeadura, densidade em torno de 80.000 plantas $\mathrm{h}^{-1}$. Não foi aplicado nenhum tipo de controle das plantas daninhas infestantes da área, após a implantação da cultura. Em abril de 2007, efetuou-se a colheita do milho.

Aos 20 e 130 DAP milho (época da colheita), procedeu-se à determinação do stand inicial e final, respectivamente, pela média do número de plantas, em quatro 
linhas de dez metros, na parcela. A altura das plantas de milho foi determinada aos 20 e 60 DAP, pela média de dez plantas, tomadas aleatoriamente em cada parcela. $\mathrm{Na}$ época da colheita (130 DAP), foram coletados dados de altura da espiga e diâmetro do colmo, também em dez plantas tomadas aleatoriamente na parcela. As espigas, colhidas numa área de 4,2 $\mathrm{m}^{2}$, demarcada aleatoriamente dentro da área útil de cada parcela, com umidade em torno de $24 \%$, foram pesadas e, em seguida, debulhadas. Os grãos foram submetidos a secagem em estufa de circulação forçada, a $72^{\circ} \mathrm{C}$, até atingirem umidade média de $11 \%$, quando foram pesados, para determinação da produção. Os resultados foram submetidos ao teste $\mathrm{F}$ da análise de variância, utilizando-se o programa estatístico Sisvar (Ferreira, 2000). As médias foram comparadas pelo Teste ScottKnott, a 5\% de probabilidade. Por contrastes, comparou-se a testemunha (pousio) e os tratamentos com cobertura.

Para avaliação da infestação de plantas daninhas, utilizou-se o método do inventário quadrado, com $0,25 \mathrm{~m}^{2}$, lançado ao acaso, duas vezes em cada parcela, aos 30 e 60 dias após o plantio do milho. As amostras coletadas para a avaliação da biomassa foram secadas em estufa de circulação forçada, a $72^{\circ} \mathrm{C}$, por 72 horas. Os dados de peso seco total de plantas infestantes em cada tratamento foram confrontados com aqueles coletados na testemunha e analisados pelo percentual de redução de biomassa das plantas daninhas, em relação ao pousio. Os resultados foram submetidos ao teste $\mathrm{F}$ da análise de variância, utilizando-se o programa estatístico Sisvar (Ferreira, 2000). Para a análise, os dados foram transformados para raiz quadrada de $\mathrm{x}+1$. As médias foram comparadas pelo Teste Scott-Knott, a 5\% de probabilidade.

Na coleta de amostra para determinação do peso seco das plantas de cobertura, utilizouse o mesmo método do inventário quadrado, com $0,25 \mathrm{~m}^{2}$, lançado ao acaso, duas vezes em cada parcela. Essas amostras foram coletadas em quatro estádios de desenvolvimento da cultura, aos 15, 30, 45 e 60 dias após o plantio do milho. Da mesma forma, procedeu-se à secagem das partes aéreas das forrageiras coletadas em estufa de circulação forçada, a $72^{\circ} \mathrm{C}$, por 72 horas. Os resultados também foram submetidos ao teste $\mathrm{F}$ da análise de variância; nesse caso, em esquema fatorial 4 x 3 x 2 (tempo x cobertura x corte). Assim, foram avaliados a variação no volume de palha produzida entre os tipos de cobertura, o efeito do corte e do tempo nas mesmas e as interações entre essas variáveis.

\section{Resultados e Discussão}

No que se refere aos dados da cultura do milho, não houve efeito significativo do 
corte para nenhum dos parâmetros analisados (Tabelas 1 a 4). Também não houve diferença significativa entre a média dos tratamentos e a testemunha (pousio), para nenhum desses parâmetros (Tabela 5).

Em se tratando do stand inicial de plântulas de milho (20 DAP), verificou-se que houve redução significativa na cobertura com braquiária, em relação ao sorgo e ao milheto, que não diferiram entre si (Tabela 1). Já na segunda avaliação de stand (130 DAP), não se constatou essa diferença. $O$ fato de o stand inicial ser inferior na cobertura de braquiária se deve a um retardamento na germinação de plântulas de milho naquele tratamento, rapidamente sanado no período subsequente à data da avaliação, razão pela qual não se observou diferença no stand final em relação aos demais tratamentos. Esse atraso pode ser proveniente do efeito alelopático provocado pela liberação de substâncias químicas no solo com a decomposição da braquiária, do efeito mecânico do volume da palha recobrindo o solo ou da conjunção dos dois fatores. Estudando a interferência de palhada de Brachiaria decumbens sobre a cultura da soja, Maciel et al. (2003) verificaram que a palhada na superfície do solo reduziu significativamente o índice de velocidade de germinação e a altura das plântulas de soja, aos cinco e aos dez dias após a emergência.

Com relação à altura de plantas, tanto aos 20 quanto aos 60 DAP, as plantas de milho na cobertura de braquiária foram superiores às plantas desenvolvidas nas coberturas de sorgo e milheto, que, por sua vez, não diferiram entre si

TABELA 1. Número de plantas de milho aos 20 e 130 dias após plantio da cultura, submetidas a três tipos de cobertura morta. Embrapa Milho e Sorgo, Sete Lagoas - MG. 2006/2007.

\begin{tabular}{|c|c|c|c|c|c|c|}
\hline \multirow{3}{*}{ Cobertura } & \multicolumn{6}{|c|}{ Plantas $\mathbf{m}^{-1}$} \\
\hline & \multicolumn{3}{|c|}{20 DAP } & \multicolumn{3}{|c|}{130 DAP } \\
\hline & C. corte & S. corte & Média & C. corte & S. corte & Médias \\
\hline Sorgo & 7,33 & 7,00 & $7,16 \mathrm{a}$ & 6,19 & 6,67 & $6,43 \mathrm{a}$ \\
\hline Braquiaria & 4,30 & 4,75 & $4,52 \mathrm{~b}$ & 6,48 & 5,77 & $6,12 \mathrm{a}$ \\
\hline Milheto & 7,01 & 7,44 & $7,22 \mathrm{a}$ & 6,04 & 6,25 & $6,14 \mathrm{a}$ \\
\hline Médias & $6,21 \mathrm{~A}$ & $6,40 \mathrm{~A}$ & & $6,24 \mathrm{~A}$ & $6,23 \mathrm{~A}$ & \\
\hline $\mathrm{CV}(\%)$ & & 14,10 & & & 11,10 & \\
\hline
\end{tabular}

DAP - Dias após plantio do milho, C.corte - Com corte na cobertura, S. Corte - Sem corte

Médias seguidas pela mesma letra minúscula, na coluna, e maiúscula, na linha, não diferem estatisticamente, pelo teste de Scott Knott, a $5 \%$ de probabilidade. 
TABELA 2. Altura de plantas de milho aos 20 e 60 dias após plantio, submetidas a três tipos de cobertura morta. Embrapa Milho e Sorgo, Sete Lagoas - MG. 2006/2007.

\begin{tabular}{|c|c|c|c|c|c|c|}
\hline \multirow{3}{*}{ Cobertura } & \multicolumn{6}{|c|}{ Altura (cm) } \\
\hline & \multicolumn{3}{|c|}{20 DAP } & \multicolumn{3}{|c|}{60 DAP } \\
\hline & C. corte & S. corte & Média & C. corte & S. corte & Médias \\
\hline Sorgo & 10,53 & 10,60 & $10,56 \mathrm{~b}$ & 174,69 & 177,81 & $176,25 \mathrm{~b}$ \\
\hline Braquiaria & 13,44 & 15,03 & $14,23 \mathrm{a}$ & 191,88 & 196,88 & 194,37 a \\
\hline Milheto & 11,38 & 11,10 & $11,23 \mathrm{~b}$ & 183,13 & 173,13 & $178,12 \mathrm{~b}$ \\
\hline Médias & $11,78 \mathrm{~A}$ & $12,24 \mathrm{~A}$ & & $183,23 \mathrm{~A}$ & $182,61 \mathrm{~A}$ & \\
\hline CV (\%) & & 11,51 & & & 8,26 & \\
\hline
\end{tabular}

DAP - Dias após plantio do milho, C.corte - Com corte na cobertura, S. Corte - Sem corte

Médias seguidas pela mesma letra minúscula na coluna e maiúscula na linha não diferem estatisticamente pelo teste de Scott Knott, a $5 \%$ de probabilidade.

(Tabela 2). Esse efeito pode ter sido provocado pelo maior volume de palha cobrindo o solo, induzindo a uma maior elongação do caule nas plântulas de milho, na tentativa de romper a camada de palha. Verificando comportamento do milho sob palhada de aveia-preta, Neves et al. (1999) observaram aumento na estatura, acompanhado de decréscimo na biomassa seca das plantas, tanto aos 20 como aos 40 dias após a emergência. Segundo os autores, tal fato decorreu em função da redução da incidência de luz sobre as plantas, resultando no desenvolvimento acentuado da sua parte aérea, fenômeno conhecido como estiolamento. De acordo com os mesmos, as alterações na qualidade e quantidade de luz, ocorridas na presença da palha, podem ter influenciado no desbalanço hormonal, especialmente nos níveis dos ácidos indolacético e giberélico, envolvidos nos processos de expansão e divisão celular, o que resultou em crescimento diferenciado das plântulas envolvidas.

Também a altura de espigas na colheita foi maior para aquelas colhidas na cobertura de braquiária (Tabela 3 ).

O diâmetro de colmo das plantas de milho, na colheita, desenvolvidas na cobertura de milheto, foi inferior em relação àquelas desenvolvidas nas coberturas de sorgo e braquiária, que, por sua vez, não diferiram entre si (Tabela 3).

Quanto aos dados de produtividade (número de espigas, peso de espigas e peso de grãos), não houve diferença significativa entre os tratamentos, pelo teste $\mathrm{F}$ da análise de variância, demonstrando que nenhuma 
TABELA 3. Altura da espiga e diâmetro de colmo de plantas de milho no período de colheita, submetidas a três tipos de cobertura morta. Embrapa Milho e Sorgo, Sete Lagoas - MG. 2006/2007

\begin{tabular}{|c|c|c|c|c|c|c|}
\hline \multirow{2}{*}{ Cobertura } & \multicolumn{3}{|c|}{ Altura de espigas (cm) } & \multicolumn{3}{|c|}{ Diâmetro do Colmo (cm) } \\
\hline & C. corte & S. corte & Média & C. corte & S. corte & Média \\
\hline Sorgo & 111,00 & 114,00 & $112,50 \mathrm{~b}$ & 1,62 & 1,70 & $1,66 \mathrm{a}$ \\
\hline Braquiaria & 124,00 & 132,00 & $128,00 \mathrm{a}$ & 1,76 & 1,71 & $1,71 \mathrm{a}$ \\
\hline Milheto & 117,00 & 121,00 & $119,00 \mathrm{~b}$ & 1,55 & 1,53 & $1,54 \mathrm{~b}$ \\
\hline Médias & $117,33 \mathrm{~A}$ & $122,33 \mathrm{~A}$ & & $1,64 \mathrm{~A}$ & $1,65 \mathrm{~A}$ & \\
\hline $\mathrm{CV}(\%)$ & & 8,50 & & & 7,09 & \\
\hline
\end{tabular}

C.corte - Com corte na cobertura, S. Corte - Sem corte

Médias seguidas pela mesma letra minúscula, na coluna, e maiúscula, na linha, não diferem estatisticamente, pelo teste de Scott Knott, a $5 \%$ de probabilidade.

TABELA 4. Número de espigas, peso de espigas e peso de grãos de milho produzidos em três tipos de cobertura de solo. Embrapa Milho e Sorgo, Sete Lagoas - MG. 2006/2007.

\begin{tabular}{|c|c|c|c|c|c|c|c|c|c|}
\hline \multirow{2}{*}{$\begin{array}{c}\text { Cober- } \\
\text { tura }\end{array}$} & \multicolumn{3}{|c|}{ Número de espigas ha-1 } & \multicolumn{3}{|c|}{ Peso de espigas ${ }^{1} \mathrm{~kg} \cdot \mathrm{ha}^{-1}$} & \multicolumn{3}{|c|}{ Peso de grãos ${ }^{2}$ kg. ha-1 } \\
\hline & C. corte & S. corte & Média & C. corte & S. corte & Média & C. corte & S. corte & Média \\
\hline Sorgo & 77900 & 76800 & $77.300 \mathrm{a}$ & 7425 & 7375 & $7.400 \mathrm{a}$ & 6225 & 6150 & $6.200 \mathrm{a}$ \\
\hline Braq. & 69025 & 67250 & $68.100 \mathrm{a}$ & 8100 & 8600 & $8.300 \mathrm{a}$ & 6750 & 7125 & $6.900 \mathrm{a}$ \\
\hline Milheto & 69025 & 82675 & $75.800 \mathrm{a}$ & 7650 & 8175 & $7.900 \mathrm{a}$ & 6350 & 6825 & $6.600 \mathrm{a}$ \\
\hline Médias & $71.983 \mathrm{~A}$ & $75.575 \mathrm{~A}$ & & $7725 \mathrm{~A}$ & $8050 \mathrm{~A}$ & & $6442 \mathrm{~A}$ & $6700 \mathrm{~A}$ & \\
\hline CV $(\%)$ & & 18,66 & & & 15,23 & & & 15,87 & \\
\hline
\end{tabular}

$124 \%$ de umidade

${ }^{2} 11 \%$ de umidade

C.corte - Com corte na cobertura, S. Corte - Sem corte. Médias seguidas pela mesma letra, na coluna, e maiúscula, na linha, não diferem estatisticamente, pelo teste de Scott Knott, a $5 \%$ de probabilidade. 


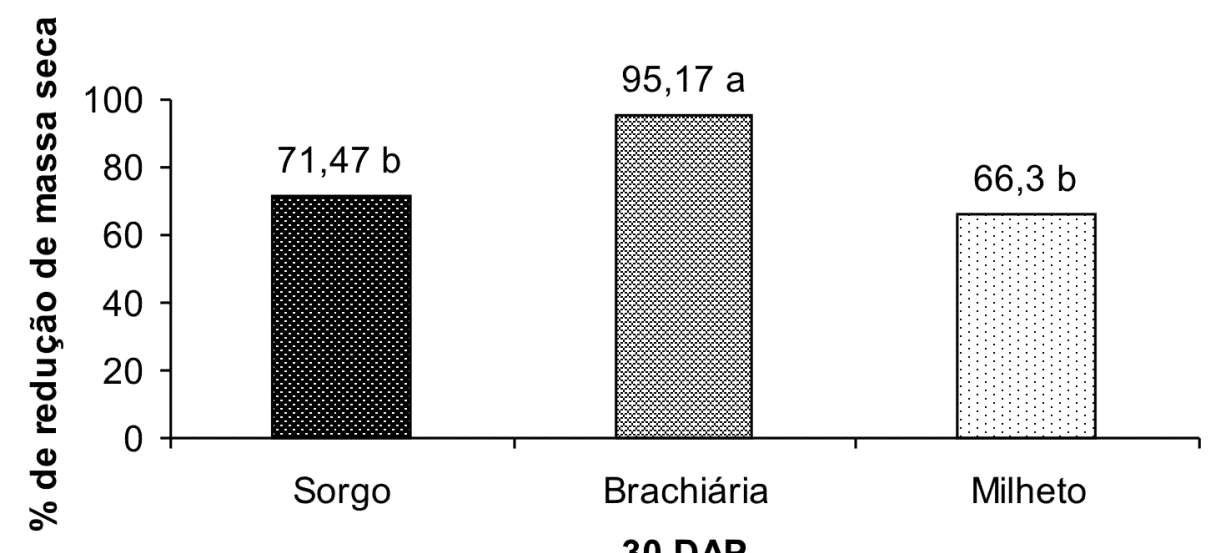

30 DAP

FIGURA 1. Porcentagem de redução na massa seca de plantas infestantes em milho sob cobertura de palhadas de gramíneas, em relação ao pousio, sem palhada, aos 30 dias após o plantio do milho (30 DAP). Embrapa Milho e Sorgo, Sete Lagoas - MG. 2006/2007.

C.V. \%: 25,26 - Médias nas colunas seguidas da mesma letra não diferem estatisticamente pelo teste de Scott Knott, a $5 \%$ de probabilidade.

das espécies de cobertura influenciou positiva ou negativamente na produtividade da cultura (Tabela 4). Avaliando características agronômicas na cultura do milho em sucessão ao próprio milho, à soja, ao girassol, ao milheto, ao sorgo e ao feijão guandu, Pasqualetto \& Costa (2001) observaram significância, pelo teste F, para altura de planta, peso de 100 grãos e umidade dos grãos na colheita. Também não foram observadas diferenças estatísticas entre as sucessões, para produtividades de grãos e demais características de produção avaliadas.

A biomassa seca média de plantas daninhas nas parcelas em pousio foi de $5,24 \mathrm{~g}$

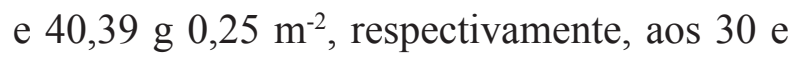
60 DAP milho. Nas três espécies de cobertura, os percentuais de redução na infestação, em relação ao pousio, foram consideráveis. Não houve diferença significativa no potencial de redução de plantas daninhas, para a variável com ou sem corte, dentro de cada espécie de cobertura, nos dois períodos de avaliação. Procedeu-se, assim, ao teste de médias entre as coberturas. Aos 30 DAP, o efeito da cobertura de capim braquiária foi superior ao sorgo e ao milheto, que, por sua vez, não diferiram entre si, no potencial de redução de plantas daninhas, em relação ao pousio (Figura 1). Em experimento onde foram comparadas sete espécies de cobertura do solo, em cultivos solteiro e consorciado, verificou-se que o capim braquiarão, em cultivo solteiro, juntamente 
TABELA 5. Comparativo dos parâmetros analisados, entre os resultados médios dos tratamentos com cobertura morta e os resultados médios das parcelas em pousio Embrapa Milho e Sorgo, Sete Lagoas - MG. 2006/2007.

\begin{tabular}{|c|c|c|c|c|c|c|c|c|c|}
\hline \multirow{2}{*}{$\begin{array}{l}\text { Trata- } \\
\text { mento }\end{array}$} & \multicolumn{2}{|c|}{ Stand Plantas $\mathbf{m}^{-1}$} & \multicolumn{2}{|c|}{$\begin{array}{c}\text { Altura de plantas } \\
(\mathrm{cm})\end{array}$} & \multirow{2}{*}{$\begin{array}{c}\text { Altura } \\
\text { espigas } \\
\text { (cm) }\end{array}$} & \multirow{2}{*}{$\begin{array}{c}\text { Diâmetro } \\
\text { Colmo (cm) }\end{array}$} & \multirow{2}{*}{$\begin{array}{l}\text { Número } \\
\text { espigas ha-1 }\end{array}$} & \multirow{2}{*}{$\begin{array}{c}\text { Peso de } \\
\text { espigas }^{1} \mathrm{~kg} . \\
\mathrm{ha}^{-1}\end{array}$} & \multirow{2}{*}{$\begin{array}{c}\text { Peso de } \\
\text { grãos }^{2} \text { kg. } \\
\text { ha }^{-1}\end{array}$} \\
\hline & 20 DAP & 130 DAP & 20 DAP & 60 DAP & & & & & \\
\hline $\begin{array}{l}\text { Cober- } \\
\text { tura }\end{array}$ & 6309 & 623 & $12,01 \mathrm{a}$ & $182,91 \mathrm{a}$ & $119,83 \mathrm{a}$ & $64 \mathrm{n}$ & 73 & $7867 \mathrm{a}$ & $6567 \mathrm{a}$ \\
\hline Pousio & $7,19 \mathrm{a}$ & $6,09 \mathrm{a}$ & 11,78 a & $198,31 \mathrm{a}$ & $115,00 \mathrm{a}$ & $1,75 \mathrm{a}$ & $81050 \mathrm{a}$ & $7575 \mathrm{a}$ & $6350 \mathrm{a}$ \\
\hline
\end{tabular}

$124 \%$ de umidade, ${ }^{2} 11 \%$ de umidade. Médias seguidas pela mesma letra minúscula, na coluna, não diferem estatisticamente, pelo teste de Scott Knott, a $5 \%$ de probabilidade.

com o mombaça (Panicum maximum), se mostraram as mais promissoras em reduzir a emergência de plantas daninhas em cultivos subsequentes (Braz et al., 2006).

Aos 60 DAP, a cobertura de capim braquiária não diferiu do milheto, sendo as duas superiores ao sorgo no potencial de redução de plantas daninhas, em relação ao pousio (Figura 2). Reduções de 80 e $75 \%$ na infestação total de plantas daninhas foram observadas por Trezzi \& Vidal (2004), em coberturas de sorgo e milheto, respectivamente, em comparação à ausência de cobertura do solo.

Vale ressaltar que os níveis de controle na infestação de plantas daninhas foram relevantes em todos os tratamentos, apesar de decrescentes da primeira para a última avaliação, época do fechamento da cultura, quando a competição não constitui mais risco para a produtividade. Tais resultados indicam que é possível o estabelecimento de estratégia de redução ou mesmo a eliminação de outros métodos de controle de plantas invasoras na cultura. Tal afirmação é corroborada por Correia et al. (2005) e também por Freitas et al. (2006), que estudaram a contribuição de palhadas de sorgo e de milheto, respectivamente, no controle de plantas daninhas na cultura da soja, associados ou não a doses de herbicidas. Ambos constataram a eficácia dessa técnica e a possibilidade de redução nas doses de herbicidas, quando utilizadas essas espécies como cobertura morta.

Ovolume de palha produzido pela espécie de cobertura e a persistência da palhada sobre o solo, além da composição, são determinantes para a eficiência do sistema no controle de plantas daninhas. A análise do volume de 


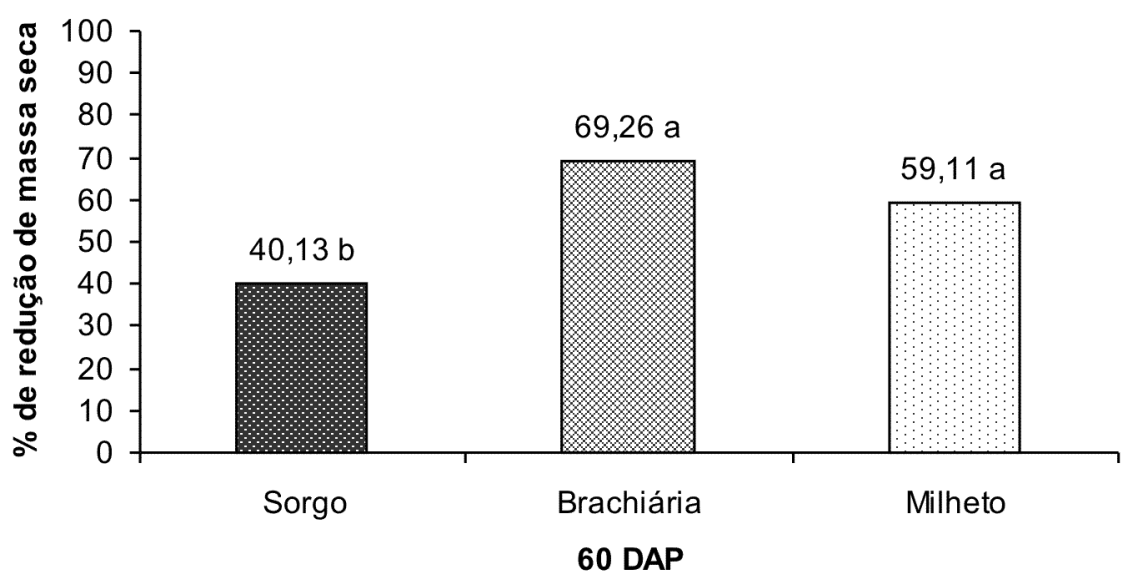

FIGURA 2. Porcentagem de redução na massa seca de plantas infestantes, em milho sob cobertura de palhadas de gramíneas, em relação ao pousio, sem palhada, aos 60 dias após plantio do milho (60 DAP). Embrapa Milho e Sorgo, Sete Lagoas - MG. 2006/2007.

C.V. \%: 37,20 - Médias nas colunas seguidas da mesma letra não diferem estatisticamente, pelo teste de Scott Knott, a $5 \%$ de probabilidade.

palha produzida mostrou que houve diferença significativa entre as espécies, sendo o volume produzido pelo capim braquiária superior ao produzido por sorgo e milheto, que, por sua vez, não diferiram entre si (Figura 3). Esse fato pode explicar a maior eficiência da cobertura de capim braquiária no controle das plantas infestantes. Em experimento com sorgo de cobertura, milheto forrageiro, braquiária e capim-péde-galinha (Eleusine coracana), com duas quantidades de palha (3,0 e 5,5 $\left.\mathrm{tha}^{-1}\right)$, mantida uma testemunha como tratamento adicional, sem cobertura com restos vegetais, Correia et al. (2006) concluíram que a composição específica e as densidades populacionais das comunidades infestantes foram influenciadas pelos sistemas de produção de cobertura morta, verificando que a emergência das plantas daninhas foi menor nas coberturas de sorgo e braquiária, nos maiores níveis de palha.

Não houve diferença significativa para os efeitos do corte e do tempo sobre o volume de palha, nem para as interações entre essas fontes de variação. Tal resultado demonstra a persistência, sobre o solo, da palha produzida por essas gramíneas, durante um período em que a cultura está mais sensível à competição por plantas daninhas. 


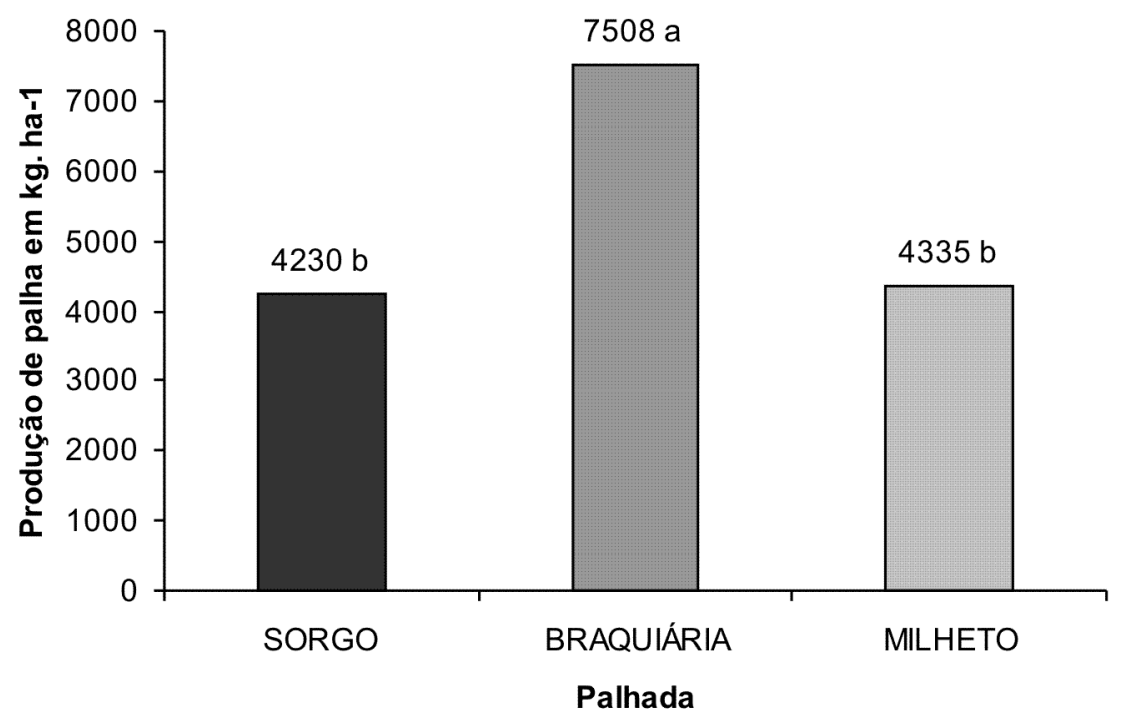

FIGURA 3. Produção de matéria seca da palhada de coberturas das gramíneas. Embrapa Milho e Sorgo, Sete Lagoas - MG. 2006/2007. C.V. \%: 47,49 - Médias nas colunas seguidas da mesma letra não diferem, pelo teste de Scott Knott, a $5 \%$ de probabilidade, MS: Matéria seca.

\section{Conclusões}

O corte da forragem não teve influência no efeito da palhada sobre a produtividade da cultura ou de sua contribuição no controle de plantas daninhas.

O capim braquiária, o sorgo tipo corte/ pastejo e o milheto podem ser utilizados para a formação de palhada, em sistema de plantio direto da cultura do milho, sem prejuízo do desenvolvimento e da produtividade da mesma.

O capim braquiária foi superior no percentual de redução da infestação de plantas daninhas e na produção de palha, indicando provável correlação entre as duas variáveis.

\section{Literatura Citada}

ALVARENGA, R. C.; CABEZAS, W. A. L.; CRUZ, J. C.; SANTANA, D. P. Plantas de cobertura de solo para sistema plantio direto. Informe Agropecuário, Belo Horizonte, v. 22, p. 25-36, 2001.

BRAZ, A. J. B. P.; PROCÓPIO, S. O.; CARGNELUTTI FILHO, A.; SILVEIRA, P. M.; KLIEMANN, H. J.; COBUCCI, T.; BRAZ, G. B. P. Emergência de plantas daninhas em lavouras de feijão e de trigo após o cultivo de espécies de cobertura de solo. Planta Daninha, Viçosa, v. 24, n. 4, p. 621-628, 2006.

CORREIA, N. M.; DURIGAN, J. C.; KLINK, U. P. Influência do tipo e da quantidade de 
resíduos vegetais na emergência de plantas daninhas. Planta Daninha, Viçosa, v. 24, n. 2 , 2006.

CORREIA, N. M.; SOUZA, I. F.; KLINK, U. P. Palha de sorgo associada ao herbicida imazamox no controle de plantas daninhas na cultura da soja em sucessão. Planta Daninha, Viçosa, v. 23, n. 3, p. 483-489, 2005.

DURIGAN, J. C.; ALMEIDA, F. L. S. Noções sobre alelopatia. Jaboticabal: FUNEP, 1993. $28 \mathrm{p}$.

ERASMO, E. A. L; AZEVEDO, W. R.; SARMENTO,R.A.;CUNHA,A.M.;GARCIA, S. L. R. Potencial de espécies utilizadas como adubo verde no manejo integrado de plantas daninhas. Planta Daninha, Viçosa, v. 22, n. 3 , p. 337-342, 2004.

FERREIRA, P. V. Estatística experimental aplicada a agronomia. 3. ed. Maceió: EDUFAL, 2000. 422 p.

FREITAS, S. P.; RODRIGUES, J. C.; SILVA, C. M. M. Manejo de plantas daninhas no plantio direto da soja (Glycine max) sobre o milheto (Pennisetum maximum). Planta Daninha., Viçosa, v. 24, n. 3, p. 481-487, 2006.

GRAVENA, R.; RODRIGUES, J. P. R. G.; SPINDOLA, W.; PITELLI, R. A.; ALVES, P. L. C. A. Controle de plantas daninhas através da palha de cana-de-açúcar associada à mistura dos herbicidas trifloxysulfuron sodium + ametrina. Planta Daninha., Viçosa, v. 22, n. 3, p. 419-427, 2004.
MACIEL, C. D. G.; CORRÊA, M. R.; ALVES, E.; NEGRISOLI, E.; VELINI, E. D.; RODRIGUES, J. D.; ONO, E. O.; BOARO, C. S. F. Influência do manejo da palhada de capimbraquiária (Brachiaria decumbens) sobre o desenvolvimento inicial de soja (Glycine max) e amendoim-bravo (Euphorbia heterophylla). Planta Daninha., Viçosa, v. 21, n. 3, p. 365373, 2003.

MATEUS, G. P.; CRUSCIOL, A. C.; NEGRISOLI, E. Gigantic guinea sorghum straw on the weed establishment in a no-tillage area. Pesquisa Agropecuária Brasileira, Brasília, DF, v. 39, n. 6, p. 539-542, 2004.

NEVES, R. N.; FLECK, N. G.; VIDAL, R.A. Establishment of corn seeding time interval after desiccation of oats with herbicides. Ciência Rural, Santa Maria, v. 29, n. 4, p. 603-608, 1999.

OLIVEIRA M. F.; ALVARENGA R. C.; OLIVEIRA A. C.; CRUZ J. C. Efeito da palha e da mistura atrazine e metolachlor no controle de plantas daninhas na cultura do milho, em sistema de plantio direto. Pesquisa Agropecuária Brasileira, Brasília, DF, v. 36, n. 1, p. 37-41, 2001.

PASQUALETO, A.; COSTA, R. M. Influência de sucessão de culturas sobre características agrnômicas do milho (zea mays 1.) em plantio direto. Pesquisa Agropecuária Tropical, Goiânia, v. 31, n. 1, p. 61-64, 2001.

TOKURA, L. K.; NÓBREGA, L. P. Potencial alelopático de cultivos de cobertura vegetal no 
desenvolvimento de plântulas de milho. Acta Scientiarum - Agronomy, Maringá, v. 27, n. 2, p. 287-292, abril/junho, 2005.

TREZZI, M. M.; VIDAL, R. A. Potencial de utilização de cobertura vegetal de sorgo e milheto na supressão de plantas daninhas em condição de campo: II - Efeitos da cobertura morta. Planta Daninha, Viçosa, v. 22, n. 1, p. 1-9, 2004.

VIDAL, R. A.; TREZZI, M. M. Potencial da utilização de coberturas vegetais de sorgo e milheto na supressão de plantas daninhas em condição de campo: I - plantas em desenvolvimento vegetativo. Planta Daninha, Viçosa, v. 22, n. 2, p. 217-224, 2004. 